Supporting Information

\title{
Effect of Hydrocarbon on DeNOx Performance of Selective Catalytic Reduction by a Combined Reductant over Cu-Containing Zeolite Catalysts
}

Iljeong Heo, ${ }^{*},{ }^{\dagger,}$ Samkyung Sung, ${ }^{\dagger, \perp}$ Min Bum Park, ${ }^{\dagger, \S}$ Tae Sun Chang, ${ }^{\dagger}$ Young Jin Kim, ${ }^{\dagger,}$ Byong K. Cho, ${ }^{\dagger}$ Suk Bong Hong, ${ }^{\dagger}$ Jin Woo Choung, ${ }^{\prime \prime}$ and In-Sik Nam*, ${ }^{\dagger}$

${ }^{\dagger}$ School of Environmental Science and Engineering, Pohang University of Science and Technology, 77 Cheongam-Ro, Pohang 37673, Korea

tResearch Center for Environment and Sustainable Resources, Korea Research Institute of Chemical Technology, 141 Gajeongro, Daejeon 34114, Korea

${ }^{\S}$ Department of Energy and Chemical Engineering, Incheon National University, 119 Academyro, Incheon 22012, Korea

"Catalysis and Chemical Systems Research Lab, Hyundai Motor Company, 150 Hyundaiyeonguso-ro, Hwaseong 18280, Korea

*Corresponding Authors: zaiseok@krict.re.kr; isnam@ postech.ac.kr 


\section{1. $\mathrm{NH}_{3} / \mathrm{SCR}$ with $\mathrm{HCs}$ as a function of time on stream and regenarability test}

Figure S1 shows the behavior of NOx conversion after the injection of $\mathrm{HC}$ during the course of the reaction on stream. At $300{ }^{\circ} \mathrm{C}$, NOx reduction activity of all catalysts tested decreased right after the $\mathrm{HC}$ injection. Then, the activity was gradually increase as time goes by and then reached to almost steady-state level at $5 \mathrm{~h}$. When $\mathrm{HC}$ was off at $20 \mathrm{~h}$, HC tolerant catalysts, CuSSZ-13 and CuMOR, restored the initial activity. On the other hand, CuZSM-5 showed incomplete restoration of NOx reduction activity, probably due to coke formation during $\mathrm{NH}_{3} / \mathrm{SCR}$ with simulated HCs. ${ }^{\mathrm{S} 1, \mathrm{~S} 2}$ After the catalyst regeneration at $500{ }^{\circ} \mathrm{C}$ on stream without HCs, CuZSM-5 also restored the initial activity at $300{ }^{\circ} \mathrm{C}$. Thus, this result additionally informs that severely poisoned catalysts by HCs lose their activity by coking which is reversibly formed and removed depending on the reaction temperature.

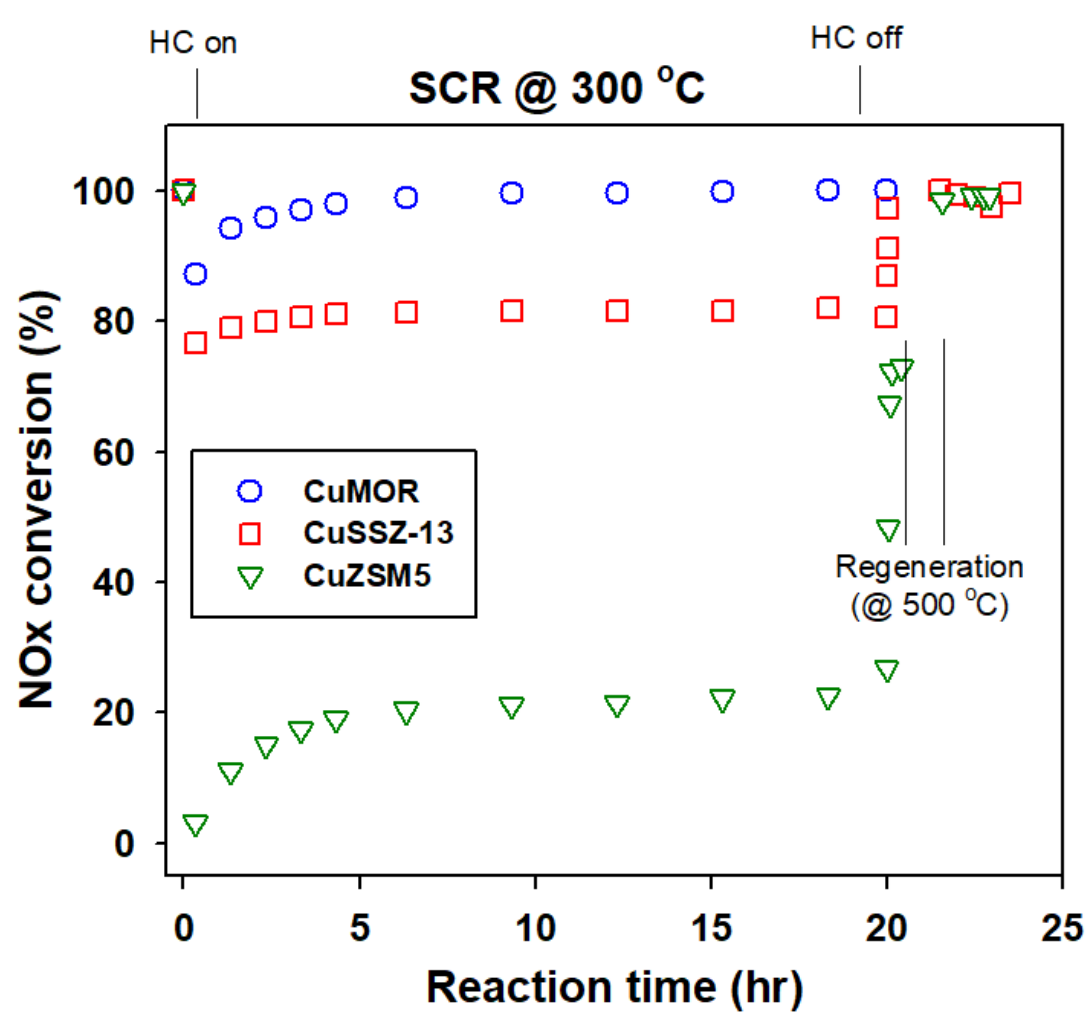

Figure S1. NOx conversion as a function of time on stream in $\mathrm{NH}_{3} / \mathrm{SCR}$ under the feed including simulated HCs. Feed gas composition: $500 \mathrm{ppm} \mathrm{NO}, 500 \mathrm{ppm} \mathrm{NH}_{3}, 5 \% \mathrm{O}_{2}, 10 \% \mathrm{H}_{2} \mathrm{O}$, simulated $\mathrm{HCs}\left(\mathrm{C}_{1}=6,000 \mathrm{ppm}\right)$, and $\mathrm{N}_{2}$ balance. Regeneration: $\mathrm{NH}_{3} / \mathrm{SCR}$ feed stream without $\mathrm{HCs}$ at 500 ${ }^{\circ} \mathrm{C}$. GHSV $=100,000 \mathrm{~h}^{-1}$. 

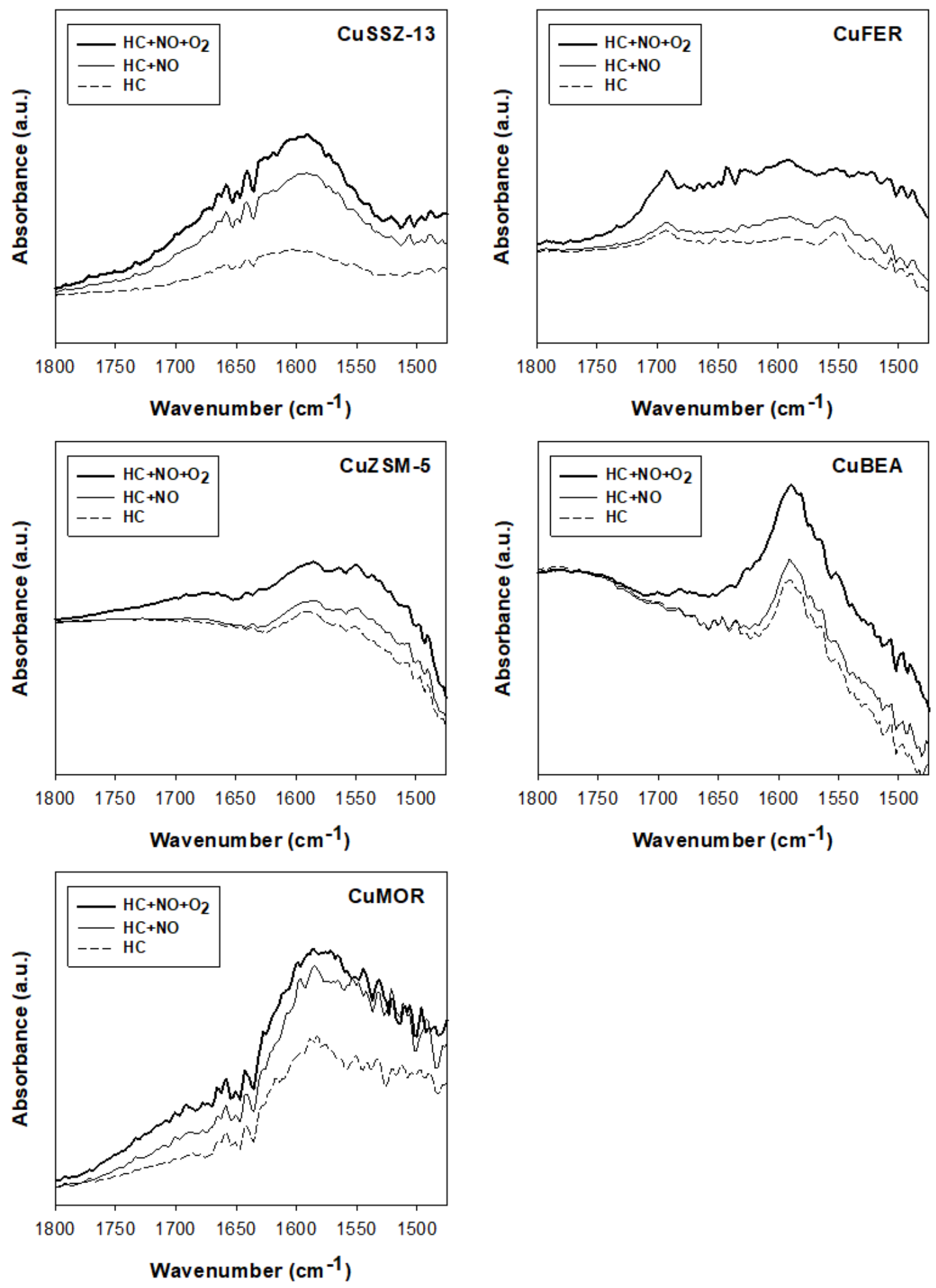

Figure S2. DRIFT spectra for adsorbed species on surfaces of $\mathrm{Cu}$ zeolite catalysts by sequential injection of reactants at $230{ }^{\circ} \mathrm{C}$. Feed gas composition: 6,000 ppm $\mathrm{C}_{1}$ of simulated $\mathrm{HCs}$, with and without $500 \mathrm{ppm} \mathrm{NO}$, with and without $5 \% \mathrm{O}_{2}$. 


\section{In-situ DRIFT study of NO adsorption and oxidation}

Effects of $\mathrm{HCs}$ on the adsorption and oxidation of $\mathrm{NO}$ on the surface of $\mathrm{Cu}$ zeolite catalysts were investigated by using in-situ DRIFT along with sequential injections of $\mathrm{HCs}, \mathrm{NO}$, and $\mathrm{O}_{2}$ to the background feed gas stream of $\mathrm{N}_{2}$ at $230{ }^{\circ} \mathrm{C}$. This sequential injection scheme resulted in a stepwise change of the feed gas composition in the following sequence: $\mathrm{HCs} \rightarrow(\mathrm{HCs}+\mathrm{NO}) \rightarrow$ $\left(\mathrm{HCs}+\mathrm{NO}+\mathrm{O}_{2}\right)$, where the concentrations of $\mathrm{HCs}$, $\mathrm{NO}$, and $\mathrm{O}_{2}$ were $6,000 \mathrm{ppm} \mathrm{C}_{1}$ of the mixed HCs, 500 ppm, and 5\%, respectively. Figure S2 shows the DRIFT spectra, which were the result of subtracting the spectrum of each activated $\mathrm{Cu}$ zeolite catalyst. Upon injection of the mixed HCs into the feed stream, all the catalysts show some broad bands in the wave number range of $1500-1800 \mathrm{~cm}^{-1}$ due to carbonaceous species such as allyl and carbonyl groups resulting from the fragmentation and/or partial oxidation of HCs by lattice oxygen of the zeolite structure. ${ }^{\mathrm{S} 3, \mathrm{~S} 4}$ On the other hand, in the sequential injection of $\mathrm{NO}$ and $\mathrm{O}_{2}$, there were almost no traces of new bands that might be associated with NO adsorption and/or surface nitrate formation. This indicates NO adsorption was strongly inhibited by the preadsorbed HCs over all the catalysts. A small additional band was observed around $1575 \mathrm{~cm}^{-1}$ only for the CuSSZ-13, where the poisoning effect of HCs is less effective. This band is corresponding to nitrate species adsorbed on the $\mathrm{Cu}$ sites. ${ }^{\text {S5,S6 }}$ It should be noted that the IR band for nitrate species was also identified even under $\mathrm{O}_{2}$ free condition, which may be due to the self-redox property of $\mathrm{Cu}$ ions at high temperature under inert gas atmosphere (see Figure S5 below).

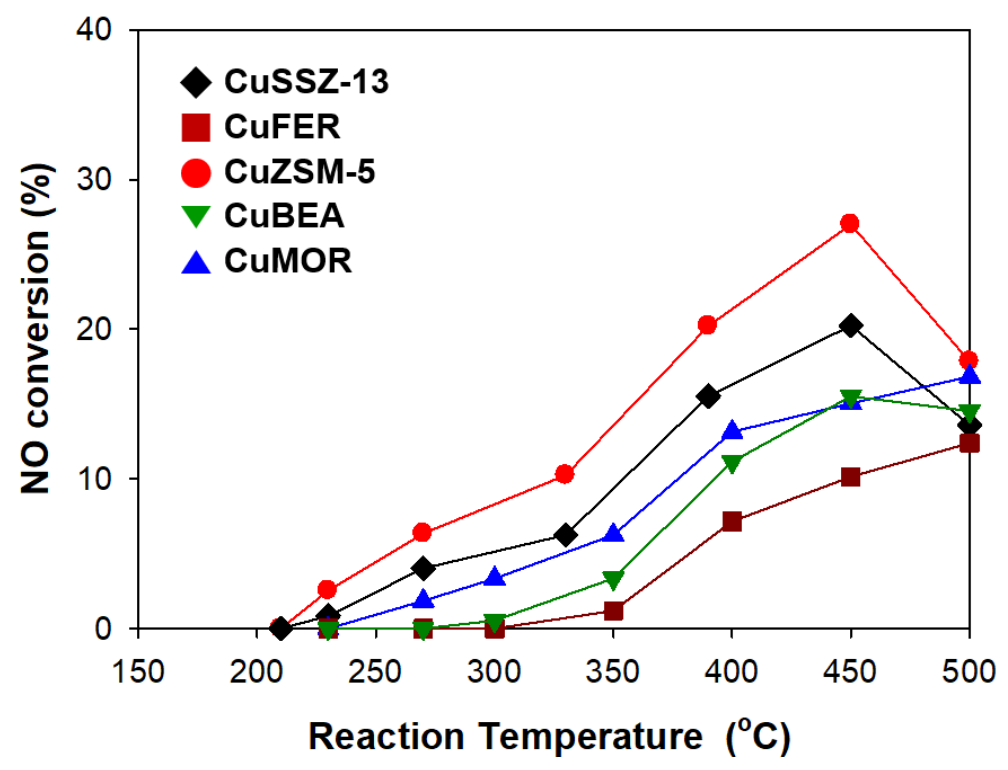

Figure S3. $\mathrm{NO}$ oxidation over $\mathrm{Cu}$ zeolite catalysts. Feed gas composition: $500 \mathrm{ppm} \mathrm{NO}, 5 \% \mathrm{O}_{2}$, $10 \% \mathrm{H}_{2} \mathrm{O}, 0$ ppm HCs, and $\mathrm{N}_{2}$ balance. GHSV $=100,000 \mathrm{~h}^{-1}$. 


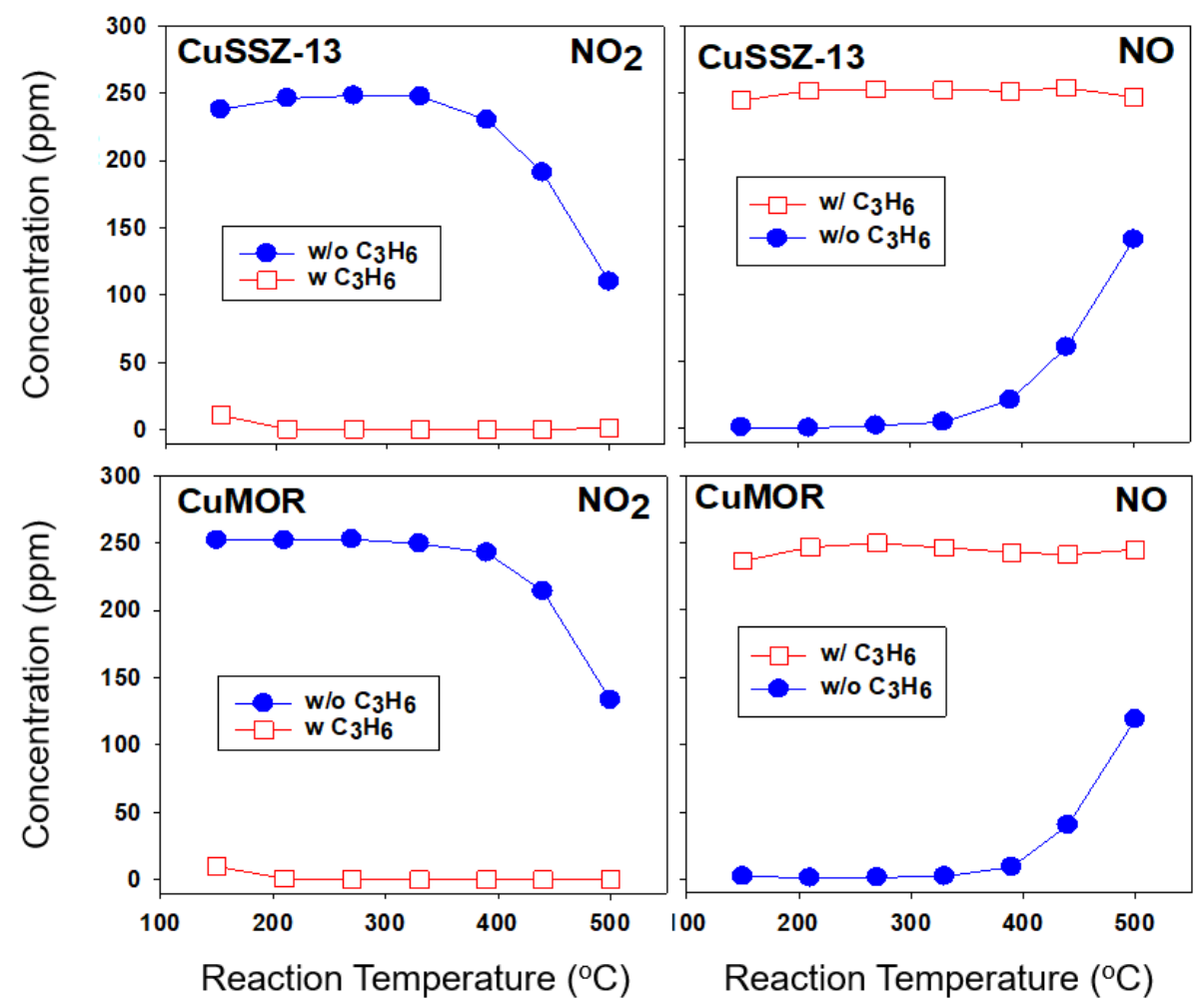

Figure S4. Variation of $\mathrm{NO}$ and $\mathrm{NO}_{2}$ concentrations by the reduction of $\mathrm{NO}_{2}$ with and without $\mathrm{HC}$ over CuSSZ-13 and CuMOR. Feed gas composition: 250 ppm $\mathrm{NO}_{2}, 5 \% \mathrm{O}_{2}, 10 \% \mathrm{H}_{2} \mathrm{O},(1,000$ ppm $\mathrm{C}_{3} \mathrm{H}_{6}$ ), and $\mathrm{N}_{2}$ balance. GHSV $=100,000 \mathrm{~h}^{-1}$.

\section{NO oxidation and $\mathrm{NO}_{2}$ reduction}

In the fresh catalyst system, the amounts of nitrates formed on the catalyst surfaces (Table 5 in the manuscript) pertain to the gaseous $\mathrm{NO}_{2}$ production rate in the lower temperature region, where adsorbed nitrate starts to be desorbed in the form of gaseous $\mathrm{NO}_{2}$, as shown in Figure $\mathrm{S} 3$. The more nitrate is formed on the catalyst surface, the more $\mathrm{NO}_{2}$ is produced at lower temperature. However, no gaseous $\mathrm{NO}_{2}$ has been observed by the direct oxidation of gaseous $\mathrm{NO}$ with simulated $\mathrm{HCs}$, regardless of the catalysts and reaction temperatures (not shown). It may be due to the reduction of $\mathrm{NO}_{2}$ formed by the $\mathrm{HCs}$ included in the feed gas stream.

The reduction of $\mathrm{NO}_{2}$ has been examined to understand the reason why no $\mathrm{NO}_{2}$ was produced by the oxidation of NO with HCs. Figure $\mathrm{S} 4$ shows the results of the $\mathrm{NO}_{2}$ reduction under oxidative condition with and without $\mathrm{HC}\left(\mathrm{C}_{3} \mathrm{H}_{6}\right)$. When $\mathrm{HC}$ is excluded in the reaction feed stream, $\mathrm{NO}_{2}$ is converted to $\mathrm{NO}$ in the temperature region higher than $390{ }^{\circ} \mathrm{C}$, regardless of the catalysts. It may be due to the reduction of $\mathrm{NO}_{2}$ to $\mathrm{NO}$ by $\mathrm{HCs}$ as well as the thermodynamic equilibrium of $\mathrm{NO} / \mathrm{NO}_{2}$ at high temperatures. ${ }^{\mathrm{S} 7}$ Indeed, $\mathrm{NO}_{2}$ is readily converted to $\mathrm{NO}$ in the 
temperature range covered in the present study (even at $150{ }^{\circ} \mathrm{C}$ ), when $1,000 \mathrm{ppm}$ of $\mathrm{C}_{3} \mathrm{H}_{6}$ is included in the feed gas stream.
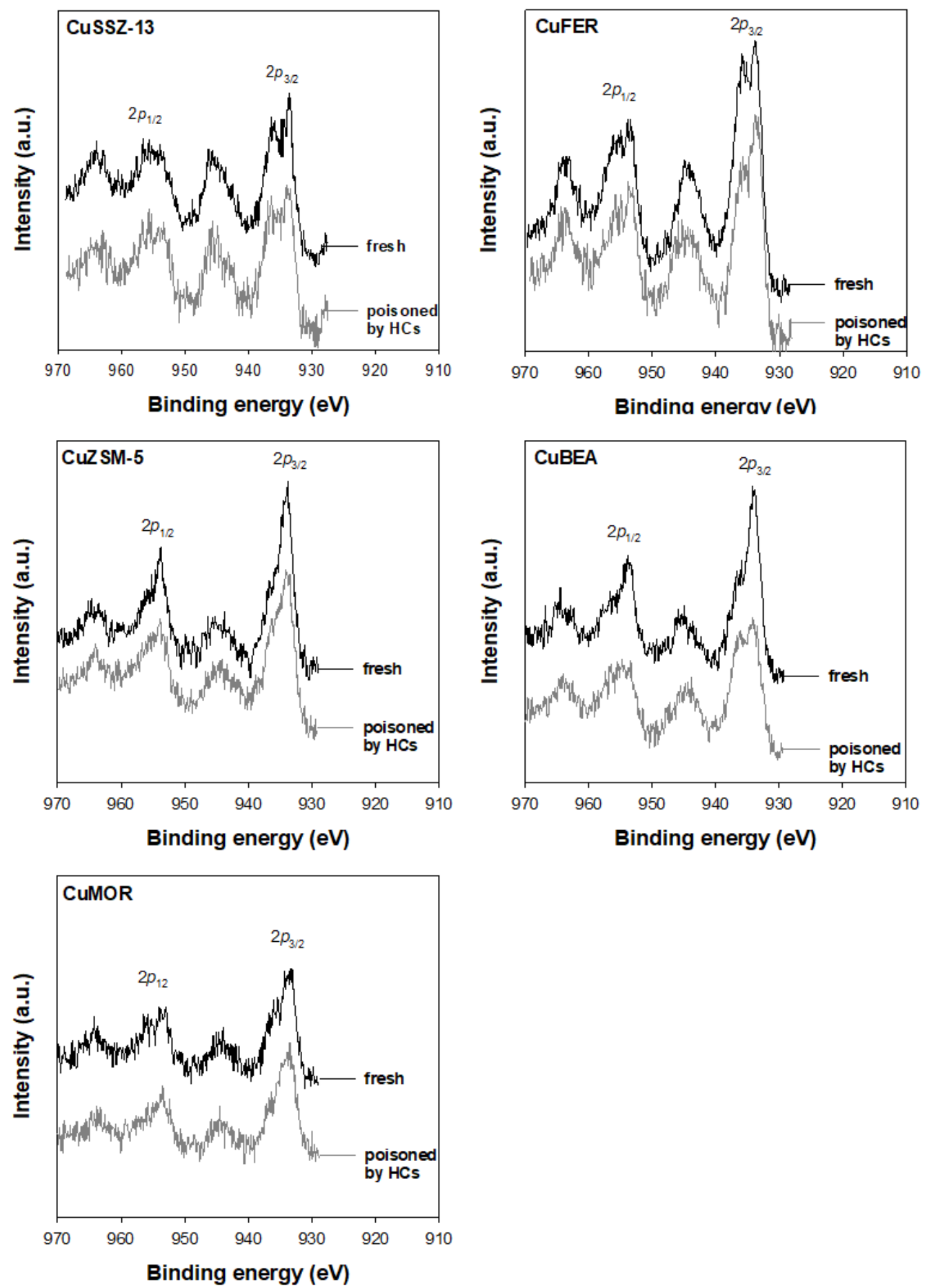

Figure S5. XPS spectra ( $\mathrm{Cu} 2 p)$ of $\mathrm{Cu}$ zeolite catalysts: fresh (top) and poisoned by mixed $\mathrm{HCs}$ (bottom). 


\section{XPS measurement}

XPS study has been conducted to examine the alteration of $\mathrm{Cu}$ state over the $\mathrm{Cu}$ zeolites after the activation under $\mathrm{He}$ flow at $500{ }^{\circ} \mathrm{C}$, and also the samples after the sequential injection of mixed HCs as an ex-situ manner. Shown in Figure S5 are the results of XPS for $\mathrm{Cu} 2 p$ before and after the $\mathrm{HC}$ adsorption. All the catalysts revealed $\mathrm{Cu} 2 p_{3 / 2}$ peaks assigned to $\mathrm{Cu}^{+}(933.7 \mathrm{eV})$, $\mathrm{Cu}^{2+}(935.6 \mathrm{eV})$, and $\mathrm{CuO}(944.5 \mathrm{eV}) .{ }^{\mathrm{S} 8, \mathrm{~S} 9}$ The relative intensity of $\mathrm{Cu}^{2+}$ is higher than that of $\mathrm{Cu}^{+}$. It is well known that the formation of $\mathrm{Cu}^{+}$is occurred on $\mathrm{Cu}$ zeolites due to the selfreduction of $\mathrm{Cu}^{2+}$ when $\mathrm{Cu}^{2+}$ ions are exposed to inert atmosphere at high temperature. ${ }^{\text {S10-S13 }}$ No shifts of the binding energies for the individual $\mathrm{Cu}$ states are observed upon the adsorption of $\mathrm{HCs}$, indicating no apparent change of the chemical states of $\mathrm{Cu}$ included in the catalysts by HCs. ${ }^{\text {S9 }}$ However, a little change of the relative peak intensity for $\mathrm{Cu}^{+}$and $\mathrm{Cu}^{2+}$ has been observed over the catalysts by the HC adsorption, probably due to the deposition of carbonaceous species originating from $\mathrm{HC}$ onto ionic copper sites. ${ }^{\mathrm{S} 14}$
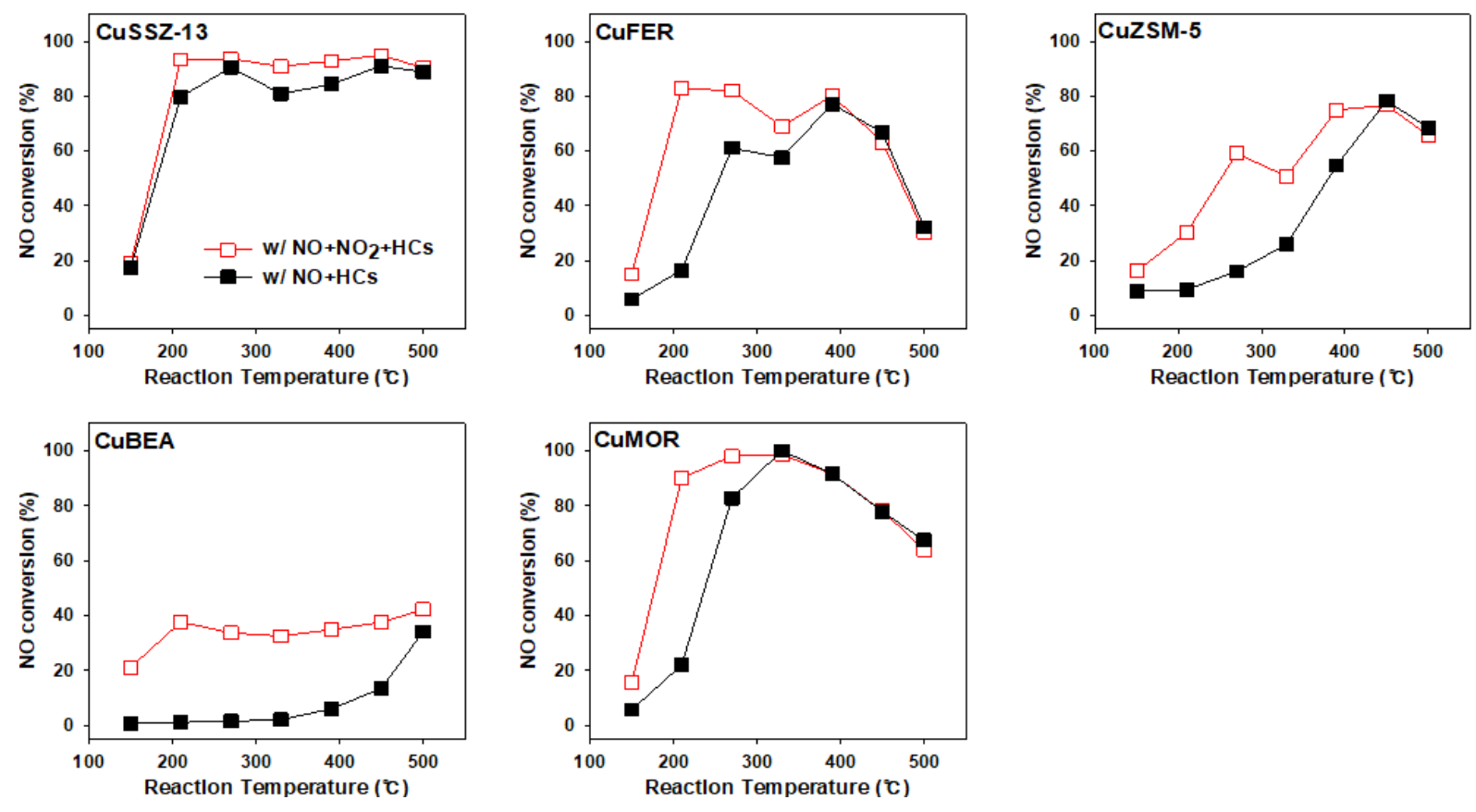

Figure S6. Effect of $\mathrm{NO}_{2}$ on deNOx performance by $\mathrm{NH}_{3} / \mathrm{SCR}$ under the feed including simulated HCs without $(\square)$ and with $(\square) \mathrm{NO}_{2}$. Feed gas composition: 500 or 250 ppm NO, 0 or

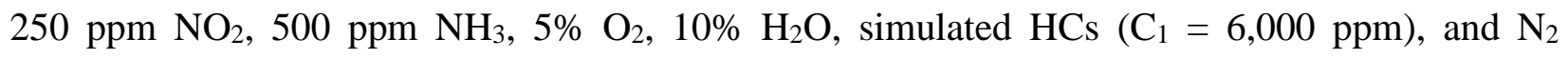
balance. GHSV $=100,000 \mathrm{~h}^{-1}$. 


\section{Effect of $\mathrm{NO}_{2}$ on deNOx performance of $\mathrm{Cu}$ zeolite catalysts by $\mathrm{NH}_{3} / \mathrm{SCR}$ with $\mathrm{HCs}$}

To further investigate the effect of the surface $\mathrm{NO}$ oxidation reaction on the $\mathrm{NH}_{3} / \mathrm{SCR}$ performance, $\mathrm{NO}_{2}$ is directly included into the reaction feed stream with simulated HCs. As shown in Figure $\mathrm{S6}$, all of the $\mathrm{Cu}$ zeolite catalysts reveal the enhancement of the deNOx performance below $300{ }^{\circ} \mathrm{C}$ by the inclusion of $\mathrm{NO}_{2}$ into the reaction feed stream with $\mathrm{HCs}$, indicating that the $\mathrm{NO}$ oxidation reaction plays an important role for the low and medium temperature SCR activities. Since the CuSSZ-13 revealed the superior NO reduction and NO oxidation reaction performances even with HCs (Figure 1 and Table 5 in the manuscript), the effect of the $\mathrm{NO}_{2}$ on the further increase of the deNOx performance seems to be insignificant. In the medium temperature region at around $330{ }^{\circ} \mathrm{C}$, most $\mathrm{Cu}$ zeolite catalysts still show the decreased $\mathrm{NO}$ conversion even with $\mathrm{NO}_{2}$ inclusion into the feed gas stream probably due to the ammoxidation reaction (Figure 5 in the manuscript), while the CuMOR reveals the nearly complete conversion of NOx at this temperature. In the high temperature region above $450{ }^{\circ} \mathrm{C}$, $\mathrm{NO}_{2}$ may not directly promote the deNOx performance of the most catalysts, probably due to the thermodynamic equilibrium of $\mathrm{NO}$ and $\mathrm{NO}_{2}$, resulting in the transformation of $\mathrm{NO}_{2}$ to $\mathrm{NO} .{ }^{\mathrm{S} 7}$

\section{References}

(S1) Luo, J.-Y.; Yeserets, A.; Henry, C.; Hess, H.; Kamasamudram, K.; Chen, H.-Y.; Epling, W. S. Hydrocarbon Poisoning of Cu-Zeolite SCR Catalysts. SAE Tech. Paper 2012, 2012-01-1096. (S2) Luo, J.-Y.; Oh, H.; Henry, C.; Epling, W. Effect of $\mathrm{C}_{3} \mathrm{H}_{6}$ on Selective Catalytic Reduction of $\mathrm{NO}_{x}$ by $\mathrm{NH}_{3}$ over a Cu/Zeolite Catalyst: A Mechanistic Study. Appl. Catal. B: Environ. 2012, 123-124, 296-305.

(S3) Heo, I.; Lee, Y.; Nam, I.-S.; Choung, J. W.; Lee, J.-H.; Kim, H.-J. Effect of Hydrocarbons Slip on NO Removal Activity of CuZSM5, FeZSM5 and $\mathrm{V}_{2} \mathrm{O}_{5} / \mathrm{TiO}_{2}$ Catalysts by $\mathrm{NH}_{3}$. Microporous Mesoporous Mater. 2011, 141, 8-15.

(S4) Socrates, G. Infrared Characteristic Group Frequencies: Tables and Charts, 2nd ed.; John Wiley \& Sons: New York, 1994.

(S5) Su, W.; Chang, H.; Peng, Y.; Zhang, C.; Li, J. Reaction Pathway Investigation on the Selective Catalytic Reduction of $\mathrm{NO}$ with $\mathrm{NH}_{3}$ over $\mathrm{Cu} / \mathrm{SSZ}-13$ at Low Temperatures. Environ. Sci. Technol. 2015, 49, 467-473.

(S6) Negri, C.; Hammershøi, P. S.; Janssens, T. V. W.; Beato, P.; Berlier, G.; Bordiga, S. Investigating the Low Temperature Formation of $\mathrm{Cu}^{\mathrm{II}}-(\mathrm{N}, \mathrm{O})$ Species on $\mathrm{Cu}-\mathrm{CHA}$ Zeolites for the Selective Catalytic Reduction of $\mathrm{NO}_{x}$. Chem. Eur. J. 2018, 24, 12044-12053. 
(S7) Kim, C. H.; Qi, G.; Dahlberg, K.; Li, W. Strontium-Doped Perovskites Rival Platium Catalysts for Treating Nox in Simulated Diesel Exhaust. Science 2010, 327, 1624-1627.

(S8) Oliva, C.; Selli, E.; Ponti, A.; Correale, L.; Solinas, V.; Rombi, E.; Monacic, R.; Fornia, L. FTIR and EPR Characterisation of Copper-Exchanged Mordenites and Beta Zeolites. J. Chem. Soc., Faraday Trans. 1997, 93, 2603-2608.

(S9) Czaplewski, K. F.; Reitz, T. L.; Kim, Y. J.; Snurr, R. Q. One-Dimensional Zeolites as Hydrocarbon Traps. Microporous Mesoporous Mater. 2002, 56, 55-64.

(S10) Larsen, S. C.; Aylor, A.; Bell, A. T.; Reimer, J. A. Electron Paramagnetic Resonance Studied of Copper Ion-Exchanged ZSM-5. J. Phys. Chem. 1994, 98, 11533-11540.

(S11) Borfecchia, E.; Lomachenko, K. A.; Giordanino, F.; Falsig, H.; Beato, P.; Soldatov, A. V.; Bordiga, S.; Lamberti, C. Revisiting the Nature of Cu Sites in the Activated Cu-SSZ-13 Catalyst for SCR Reaction. Chem. Sci. 2015, 6, 548-563.

(S12) Paolucci, C.; Parekh, A. A.; Khurana, I.; Di Iorio, J. R.; Li, H.; Albarracin Caballero, J. D.; Shih, A. J.; Anggara, T.; Delgass, W. N.; Miller, J. T.; Ribeiro, F. H.; Gounder, R.; Schneider, W. F. Catalysis in a Cage: Condition-Dependent Speciation and Dynamics of Exchanged Cu Cations in SSZ-13 Zeolites. J. Am. Chem. Soc. 2016, 138, 6028-6048.

(S13) Sushkevich, V. L.; van Bokhoven, J. A. Revisiting Copper Reduction in Zeolites: The Impact of Autoreduction and Sample Synthesis Procedure. Chem. Commun. 2018, 54, 7447-7450. (S14) Brosius, R.; Martens, J. A. Reaction Mechanisms of Lean-Burn Hydrocarbon SCR over Zeolite Catalysts. Top. Catal. 2004, 28, 119-130. 